\title{
Scenario-Based Analysis on the Structural Change of Land Uses in China
}

\author{
Qian Xu, ${ }^{1}$ Qunou Jiang, ${ }^{2}$ Kai Cao, ${ }^{1}$ Xing Li, ${ }^{1}$ and Xiangzheng Deng ${ }^{3,4}$ \\ ${ }^{1}$ School of Mathematics and Physics, China University of Geosciences (Wuhan), Wuhan 430074, China \\ ${ }^{2}$ School of Soil and Water Conservation, Beijing Forestry University, Beijing 100038, China \\ ${ }^{3}$ Institute of Geographic Sciences and Natural Resources Research, Chinese Academy of Sciences, Beijing 100101, China \\ ${ }^{4}$ Center for Chinese Agricultural Policy, Chinese Academy of Sciences, Beijing 100101, China \\ Correspondence should be addressed to Qian Xu; xq_dls@163.com
}

Received 17 July 2013; Accepted 26 September 2013

Academic Editor: Burak Güneralp

Copyright (c) 2013 Qian Xu et al. This is an open access article distributed under the Creative Commons Attribution License, which permits unrestricted use, distribution, and reproduction in any medium, provided the original work is properly cited.

Land Use/Land Cover change (LUCC) is a key aspect of global environmental change, which has a significant impact on climate change. In the background of increasing global warming resulting from greenhouse effect, to understand the impact of land use change on climate change is necessary and meaningful. In this study, we choose China as the study area and explore the possible land use change trends based on the AgLU module and ERB module of global change assessment model (GCAM model and Global Change Assessment Model). We design three scenarios based on socioeconomic development and simulated the corresponding structure change of land use according to the three scenarios with different parameters. Then we simulate the different emission of $\mathrm{CO}_{2}$ under different scenarios based on the simulation results of structure change of land use. At last, we choose the most suitable scenario that could control the emission of $\mathrm{CO}_{2}$ best and obtain the relatively better land use structure change for adaption of climate change. Through this research we can provide a theoretical basis for the future land use planning to adapt to climate change.

\section{Introduction}

LUCC is a significant performance of the material and energy interactions between human and global environment [1-3]. It not only affects the geographical distribution of terrestrial ecosystem patterns and productivity but also objectively reflects how human influence biogeochemical cycles and the structure and function of ecosystem [4-7]. Land use refers to all the activities to develop and utilize the land use on purpose; for example, agricultural land, industrial land, traffic land, residential land, and so forth, are all the land use types. Advanced methods have also been used by scholars in the classification of land use; Jiang et al. used the ANN and Dempster-Shafer theory to get a more detailed classification of land use [8]. LUCC is one of the International core research program of International Geosphere-Biosphere Programme (IGBP) and the Global Environmental Change Human Dimensions Programme (IHDP), which also is one of the new research field and global environmental research focus in earth system science [9]. A lot of scholars had come to realize the important research significance of LUCC, and some studies showed that there was a very close relationship between land use changes and climate change. Dale pointed out that land use change was related to climate change as both a causal factor and a major way in early 1994 [10]. Studies of Hao and Ren showed that LUCC had a profound influence in climates, biogeochemistry, and biological diversities; the response of ecoenvironment to LUCC had become the core problems both in the fields of global climate change research and land use change research [11].

LUCC was the core of all related sustainable development issues; according to the IGBP and IHDP research reports, social and economic driving force could be divided into direct and indirect factors and the indirect factors included demographic change, affluence, technological development, political economy, political structures, views, and values [12]. Scholars conducted a lot of research on LUCC to reveal the relationship of land, environment, population, and social development. Then it could promote the precision of simulation and prediction for the land use change on the base 
of grasping the causal relationship between socioeconomic driving forces and land use, which would offer the references for the rational utilization of land resources [13].

According to the latest study results of the 2012 United Nations Environment investigation team, the emission of $\mathrm{CO}_{2}$ had become the main research compared with other global greenhouse gas, and its share of total greenhouse gas emissions reached more than $80 \%$. With global warming becoming increasingly serious, it is urgent to mitigate the climate worsening. Controlling $\mathrm{CO}_{2}$ emissions is becoming more and more important. Therefore, from then on, the impact of land use change on climate change draws more and more attention to researchers. Bonan analyzed the driving mechanism of climate change for the forestry area changes [14]. Wang et al. studied the effects of urbanization level on climate change, and the results showed that urbanization would cause the temperature growth [15]. Kalnay and Cai had also revealed that half of decrease observed in diurnal temperature was influenced by urban and land use changes [16], which reflected human activities playing important driving forces role on climate change.

With the development of economy and the increasing of population and resource consumption, the environment in China has gradually degraded. Zhuang et al. considered the impacts on land use from the view of energy supply by a multifactor analysis and proposed a combined planting zonation strategy [17]. Anderson et al. studied the influences of climate change on agricultural economy [18]. Li et al. proposed an evaluation approach to assess urban sustainable development by measuring indicators for supporting urban ecological planning [19]. Hu et al. studied the low-carbon development of China and gave an outlook of China's economy growth, energy-electricity demand, renewable power generation, energy conservation, and emissions mitigation until 2030 in an Economy-Energy-Electricity-Environment (E4) coupled framework [20]. Zhang et al. took a meticulous research to quantify the relationships among economic growth and energy consumption and $\mathrm{CO}_{2}$ emission, and showed that there were sensitive impacts among them [21]. These studies had revealed that there were a close link among human activities, land use change, and climate change through different horizons, and applied different methods to find out an appropriate economic development route.

In this study, China as the study area, we studied how LUCC influence $\mathrm{CO}_{2}$ emissions and tried to reveal the function of LUCC to $\mathrm{CO}_{2}$ emissions. To achieve the goal above, AgLU module of GCAM model was applied to simulate land use changes in the future and then combined with ERB module to simulate $\mathrm{CO}_{2}$ emissions based on the simulated land use change. Results of this study showed that socioeconomic factors play an important role in land use change and climate change. We came out with that coordinated environmental sustainability scenario (CES) is the more proper scenario, which not only protects the environment, but also promotes the economic development. In CES scenario, it reflects the sustainable development, which is more suitable for the development of China. Therefore, through the comparison of scenarios' results, we can obtain the more suitable sustainable development route of China based on the future structural change of land uses, which is meaningful to achieve the goal of sustainable development.

\section{Data}

2.1. Land Use Data. In the paper, we used TM/ETM images from 1990 to 2010 as the data source, which were derived from the Resources and Environment Data Center of the Chinese Academy of Science [22]. The Landsat TM/ETM (Enhanced Thematic Mapper) data were further grouped into six aggregated classes of land cover, we used the five types land use: cultivated lands, forest lands, grasslands, unused land, and built-up areas including urban areas. Cultivated lands include paddy and dry farming land. Forest lands include forest, shrub, and others (e.g., orchards). Grasslands include three density dependent types: dense, moderate, and sparse grass. Unused land includes sandy land, Gobi, Salina, wetland, bare soil, bare rock, and others such as alpine desert and tundra. Built-up land includes urban area, rural settlements, and others such as roads and airports.

2.2. Socioeconomic Data. Socioeconomic data include the population, population density and growth rate of per capita income, the proportion of agricultural population, urbanization ratio, GDP, and price index of oil, gas, coal, and hydropower, from 1990 to 2010. Among them, population, GDP, population density, proportion of agricultural population, and urbanization ratio are derived from the Statistical Yearbook of China and the provincial statistical data [23]. Price index of natural gas, coal, and hydropower are mainly extracted from the Energy Statistics Yearbook; average household income growth ratio is obtained by looking for literatures and other relevant information, which reached about $11.24 \%$ from 1990 to 2010. Population, average income growth ratio, and commodity market prices are the main parameters of AgLU module; the relevant specific data will be given in the section of scenario design.

\section{Methods}

3.1. GCAM Model. The GCAM model is an integrated assessment model of moderate complexity focused on energy and agriculture sectors and a long-term, partial-equilibrium model designed to examine long-term, large-scale changes in global and regional energy system where the characteristics of existing capital stocks are not the dominant factor in determining the dynamics of the energy system. The markets in GCAM are defined for oil, gas, coal, biomass, carbon, and agricultural products. Driven by the factors, such as population, labor productivity growth, and the supply and demand of resources in market, the goal of optimal land use allocation can be achieved through AgLU module. Besides, through incorporation of the ERB module, the emissions of greenhouse gases can be calculated [24].

The GCAM model can be conceptualized as consisting of four modules: Edmonds-Reilly-Barnes model (ERB [25-27]), Agriculture and Land Use model (AgLU [28, 29]), Model for the Assessment of Greenhouse-gas Induced Climate Change (MAGICC [30]), and Regional Climate Change Scenario Generator (SCENGEN [31]) (Figure 1). 


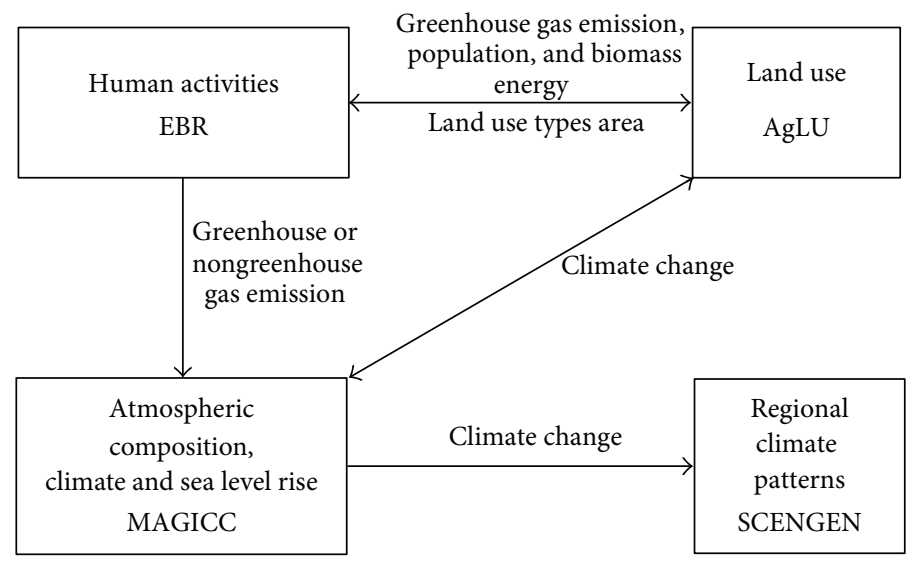

FIgURE 1: The framework of GCAM model.

3.2. Land Allocation. The land allocation diagram shows how land is allocated among alternative land uses. Selection of land use is based on maximizing economic return at each location. Profit per hectare is equal to revenue (yield per hectare times price received) minus production cost (yield per hectare times nonland cost per unit of output). This relationship is shown in (1)

$$
\pi r_{i, l, m, p}=y_{i, l, m, p} \cdot\left(P_{i, l, m}-G_{i, l, m}\right),
$$

where $\pi r_{i, l, m, p}$ is the economic return of the land as a profit rate $(\$ / \mathrm{ha} \cdot \mathrm{yr}) ; y_{i, l, m, p}$ is yield per hectare for land use $i$ in region $j$ at location $p$ (calories/ha); $P_{i, l, m}$ is the market price for the product produced by land use $i$ (units $\$ /$ yield units: calories or $\left.\mathrm{m}^{3}\right) ; G_{i, l, m}$ is the nonland cost per unit of output in land use (units are $\$ /$ yield units: calories or $\mathrm{m}^{3}$ ), $i$ is an index for land use type, $l$ is the region index, and $p$ is an index for geographical location within a region.

The profit rate $(\pi r)$ calculation for forest products is somewhat different because of the time lag between planting and harvest. The profit rate expression for forest products includes a term that discounts future earnings into the present and levelizes those earnings over 45 years; this forward price is denoted by $\bar{P}_{i, l, m}$,

$$
\pi r_{i, l, m, p}=\frac{r}{(1+r)^{45}-1} \cdot\left(\bar{P}_{i, l, m}-G_{i, l, m}\right)
$$

where $r$ is the interest rate ( $\$ / \$$ that is unitless).

To determine the share of land allocated to each land use type, land use shares would, in general, be calculated numerically, by summing over the land distributions implied in (1) and (2). In the usual integrated modeling context, however, we wish to work on large regional scales. We used instead a reduced-form expression for land shares that effectively sums over the index $p$ in (1) and (2) based on maximizing profit rates which is at the core of finding land shares that provide the yields leading to maximum profits.
With specific assumptions on the functional form of the yield distribution, the share of land allocated to use $i$ is given by a logit share equation:

$$
S_{i, l, m}=\frac{\bar{\pi} r_{i, l, m}^{1 / \lambda}}{\sum_{p} \bar{\pi} r_{i, l, m, p}^{1 / \lambda}},
$$

where $\lambda$ is a positive parameter that determines the rate that land shares change in response to a change in profit rate. $\bar{\pi} r_{i, l, m}$ is the average profit rate using land $i$, which is the profit rate evaluated at an average or intrinsic yield, $\bar{y}_{i}$, for land use i.

Land use for a specific purpose is calculated based on this logit-based share of total land:

$$
{\text { Land } \text { use }_{i, l, m}=S_{i, l, m} \cdot \text { Total land }}_{l} \text {. }
$$

3.3. $\mathrm{CO}_{2}$ Emissions. Carbon emissions are accounted for in two separate categories, those from industry and fossil fuel use and those as net land-use emissions. This is necessary because land-use emissions have different implications for the carbon-cycle than industrial emissions. Industrial emissions are the sum of emissions from fossil-fuel production and from cement production.

3.3.1. $\mathrm{CO}_{2}$ Emissions from the AgLU Module. Carbon emissions from land-use change are calculated as the difference in carbon stock between periods. The land allocated to crops, pasture, forests, commercial biomass, and unmanaged land changes over time in response to changing demands, income, agricultural technologies, and prices of agricultural products. Each regional land-use category is assigned a carbon density for soils and above ground plant material. Changes in land use are translated directly to changes in carbon stocks with net carbon emissions equal to the product of land use changes multiplied by carbon densities for each land-use class. Historical land use changes are used when vegetation change and soil emissions are calculated for the first time period and for soils when the more refractory carbon decays (slower) in subsequent time periods. 
For crops, pasture, forests, and unmanaged land the carbon emissions from above ground are calculated as follows:

$$
\mathrm{EmLC}_{i, l, m}=\sum_{l=1}^{n r}\left(\mathrm{CLdens}_{l, i} \cdot \frac{\text { Land use }_{i, l, m}-\text { Land use }_{i, l, m-1}}{N \text { step }}\right),
$$

where $i$ is an index for land use: crops, pasture, forests, and unmanaged land.

For soils the carbon emissions are not only based on changes in land use but also on a fractionation of the carbon according to decay rates. Thus, $60 \%$ of the soil carbon is assumed to decay when land use change occurs during the simulated time period $\left(P d_{0}=0.6\right) ; 30 \%$ of the soil carbon is assumed to only decay in the next time period $\left(P d_{-1}=0.3\right)$, and $10 \%$ of the soil carbon is assumed to decay during the second time period 30 years after the land use change occurs $\left(P d_{-2}=0.1\right)$.

Consider

$$
\begin{aligned}
& \mathrm{EmSC}_{i, m} \\
& =\sum_{l=1}^{n r}\left[\sum _ { m = m - 2 } ^ { m } \left(\operatorname{CSdens}_{l, i} \cdot P d_{m}\right.\right. \\
& \left.\left.\cdot \frac{\text { Land }_{\text {use }}-\text { Land use }_{m-1}}{\text { Nstep }}\right)\right] \text {. }
\end{aligned}
$$

3.3.2. $\mathrm{CO}_{2}$ Emissions from ERB Module. In the ERB module carbon dioxide emissions from fossil fuel use are calculated after global fuel demands have been determined. Emissions are equal to the carbon emission coefficient times the amount of fuel used. Emissions associated with energy transformations (synthetic fuels, electricity generation, and hydrogen production) are allocated to the region where the transformation occurs.

Conventional oil, gas, coal, and biomass emissions are calculated as follows, which include, if the RemFrac R $_{2, l}$ parameter is not equal to zero, carbon removal through scrubbing by utility scrub technology and hydrogen production scrub technology. Emissions from direct biomass burning are set to zero in most scenarios; however,

$$
\begin{aligned}
& \mathrm{EmSC}_{i}= \mathrm{CO}_{i} \\
& \cdot\left[\mathrm{FFcons} \cdot\left(1-\mathrm{SedFil}_{i, l}\right)-\mathrm{RemFrac}_{2, l}\right. \\
&\left.\quad \cdot\left(\mathrm{ESU}_{u i, l, m} g u_{u i, l, m} g i j_{i}+\mathrm{ESH}_{h i, l, m} g h_{h i, l, m} g i j_{i}\right)\right],
\end{aligned}
$$

where $\mathrm{CO}_{i}$ is the emission coefficient of oil, gas, coal, or biomass; SedFil ${ }_{i, l}$ is the fraction of the feedstock that is not combusted; RemFrac $2, l$ is the fraction of the emissions that can be scrubbed during electricity and/or hydrogen generation; $\mathrm{ESU}_{u i, l, m}$ is the energy in Joules that needs to be combusted as secondary energy, electricity, to meet demand and that needs to be converted to primary energy for emission calculations by multiplying with the conversion coefficients $g u_{u i, l, m}$ and $g i j_{i} ; \mathrm{ESH}_{h i, l, m}$ is the energy in Joules that needs to be combusted as secondary energy, hydrogen, to meet demand and that needs to be converted to primary energy for emission calculations by multiplying with the conversion coefficients $g h_{h i, l, m}$ and $g i j_{i} ; g h_{h i, l, m}$ is the transformation efficiency when electricity and hydrogen is produced; $g i j_{i}$ is the transformation efficiency from primary to secondary fuel conversion; and FFcons equals the primary fuel demanded for transformation into secondary fuel supply.

For each of the end-use sectors emissions are based on fuel mode demands, attributing shale oil production emissions and flared emissions to the industrial sector. Thus, for transportation, buildings, and industry, consider the following:

$$
\mathrm{EmSC}_{k}=\sum_{j} \mathrm{CO}_{j} \cdot \mathrm{Fjk}_{j, k, l, m} \cdot\left(1-\mathrm{SedFil}_{j, l}\right),
$$

where $\mathrm{CO}_{j}$ is the emission coefficient of oil, gas, coal, or biomass; SedFil ${ }_{j, l}$ is the fraction of the feedstock that is not combusted; Fjk ${ }_{j, k, l, m}$ is the primary fuel demands.

\section{Scenarios}

4.1. Socioeconomic Analysis on China. With a rapid development of economy in China in the past 30 years, GDP has a great increase, from 364.52 billion Yuan at the beginning of reform and opening up to 34.05 trillion Yuan in 2009, with an average annual GDP growth rate of $9.6 \%$ which is far higher than those of other countries in the period of economic takeoff. Meanwhile industrialization and urbanization developed rapidly, urbanization level rose from $18 \%$ in 1978 to $46.6 \%$ in 2009 , and it will reach $65 \%$ by 2030 . Urbanization and the resultant expansion of urban population will directly bring about the growth of consumer demand, on the one hand, and put forward more requirements for urban infrastructure investment on the other hand. The development of industrialization and urbanization will certainly exacerbate some structural contradictions, which will raise the cost of labor, land, natural resources, and social undertakings. However, industrialization and urbanization are still the main internal drives for economic growth for a long time.

China's population has stepped into the modern population growth phase with the character of "low birthrate, low death rate, and low growth" since the early 21th Century. Some studies have shown that the number of population will reach the peak around 2030 and then the total population may begin to gradually decline and it will enter the a negative growth phase. After 2015, China's working-age population has been declining, and China's labor supply will gradually decline in the next 20 years.

According to preliminary statistics report released by National Bureau of Statistics, the proportion of the added value of first, second, and tertiary industry to GDP was $10.2 \%, 46.9 \%$, and $42.9 \%$ in 2010 . In comparison to 1990 , the proportion of primary industry decreased by $16.9 \%$, while the secondary industry and tertiaries industry increased by $5.6 \%$ and $11.4 \%$, respectively. Overall, the industrial structural changes in the past 20 years sustained the main changing characteristics as it was since the 1970s in China; namely, the proportion of primary industry was declining, the secondary 
industry consolidated its position, and the tertiary industry has been significantly increasing. In addition, the industrial structure will be further optimized in the future.

As the continuous expansion of global economic development scale, the demand for resources and energies will continue to grow; the supply-demand balance of resources and energy also has an important influence on energy and resource prices such as oil, natural gas, coal, and other major energy. Since 1978, the proportion of China's hydropower consumption in primary energy consumption increased year by year, increased from $3.4 \%$ in 1978 to $7.2 \%$ in 2005. In 2008, coal accounted for 67\%. According to China Statistical Yearbook, in 2009 in China the total energy production was 2.75 billion tons, while the consumption have reached 3.07 billion tons, so there was a gap between consumption and demand. Meanwhile, in China's total energy productions, coal and oil accounted for a large share, in which the percentage of coal was $70.4 \%$, the oil was $17.9 \%$, and natural gas accounted for only to $3.9 \%$. While the hydropower, nuclear power, and wind power are relatively slow growth and only accounted for $7.8 \%$ of total. However, with the gradual lack of resources and energy, the impacts and constraints of the resources and energy on human socialeconomic development will become more and more obvious. According to the forecasts of International Energy Agency and the US Department of Energy, despite global demand for energy resources continuously grew between 2005 and 2030, the overall supply and demand will be close to equilibrium in the future.

4.2. Scenarios Design. According to the characteristics of socialeconomic development in the past 30 years, we design three kinds of socialeconomic development scenarios, that is, Business as usual scenario (BAU), Rapid economic growth scenario (REG), and coordinated environmental sustainability scenario (CES).

Firstly, the BAU scenario is designed according to the economic development process and the structural characteristics in China combining the factors with the most possible changes such as population, factor endowments, and technological advances. This kind of scenario reflects the likely changing trends of socialeconomic development and also provides a reference which can be compared with other scenarios. Then we design the REG scenario to explore the land use change under the development mode of accelerating the socialeconomic development. In addition, taking into account the future challenges faced by domestic development as well as growing environmental pressures in the future, the CES scenario is also designed to simulate the possible land use changing trends under the combined effect of these risk factors.

4.2.1. BAU Scenario. In a long term, changes in labor supply, investment and improvement in productivity, determine the overall economic growth situation. Labor supply depends on the total population and population age structure, while the corresponding total population age structure and the total labor change have significant effects on the labor force immigration. Population growth is impacted by plenty of factors such as the family planning policy, improvement of people's living standards, lifestyle changes, and so on, but the main influence factor is the national population policy. In this study, population growth is exogenous variable and the forecast population data are from the CASS and Institute of Population and Labor Economics is applied. According to this forecast, China's population peak will occur in 2037 with a population of about 1.47 billion, while the workingage population peak will appear in 2017-2027 with about 10 million. According to the proportion of labor forces to the working-age population labor in 2006, the total labor resources in the whole country will be the about 820 million at the moment when the working-age population is in the peak, and it will increase by 40 million in comparison to 2006 .

Productivity improvement is mainly reflected as total factor productivity (TFP) changes in the model. Through studies on total factor productivity in the past 30 years, it can be found that there are amounts of factors affecting the TFP in China, such as institutional reform, human capital spillover effect, technological capital, market reform, urbanization, foreign investment effect, foreign trade effect, infrastructure and administrative costs, final consumption rate, and so on. Although the specific quantitative research results have obvious differences, most of the studies show that the average annual growth rate of TFP in China is between $2 \%$ and $4 \%$. From a long-term perspective, some significant factors of promoting the TFP growth will continue to play an important role; for example, system reform will further be deepened, urbanization will steadily be pushed forward, the rural labor force will continue to be migrated, human capital will be accumulated, and so on. Therefore, in the BAU scenario, the model assumes that the average annual growth rate of TFP continues to follow the development ratio in the past during 2008-2050 and remain at the level of about $2 \%$.

China's demand for energy has surged to fuel its rapidly expanding industrial and commercial sectors as well as households experiencing rising living standards. B. Lin research showed that from 1999 to 2008, the average growth rate of coal production of China was $11.37 \%$, which was almost twice as much as that of 5.81\% from 1982 to 1996, In 2008, coal production in China rose to 2716 million tons ( $40 \%$ of global coal production) [32]. Studies of Liu et al. showed that the average energy consumption has risen by $5.2 \%$ since 1978 , while during $2001-2007$, the primary energy consumption has soared through an average annual increase of $9.8 \%$, and the GDP has increased by $10.2 \%$ in the same period [33]. Besides, the Chinese Academy of Social Sciences takes consideration of population growth, economic growth and structural change, technological progress, environmental impact and energy security, and other factors predicted modeling results; in 2050 primary energy demand will reach $3440 \mathrm{Mtce} 41502 \mathrm{Mtce}$. The structure of energy get improved significantly, and the proportion of coal in primary energy consumption from 60\% in 1990 (excluding biomass $76.2 \%$ ) declined to $47.7 \%$ in 2050 (51.9\%), while oil and gas from $14.8 \%$ (18.7\%) increased to $26.3 \%$ (28.6\%). Primary energy supply capacity would increase from 1302 Mtce in 1990 to 2980 Mtce 3740 Mtce in 2050 , where: coal 2500 Mtce $2700 \mathrm{Mtce}$, crude $100 \mathrm{Mt} 200 \mathrm{Mt}$, and natural gas 120 billion cubic meters to 1,400 cubic meters. 
TABLE 1: Economic growth under the BAU scenario in 2008-2100 (unit: \%).

\begin{tabular}{lccccccccc}
\hline & $2008 \sim 2010$ & $2011 \sim 2015$ & $2016 \sim 2020$ & $2021 \sim 2025$ & $2026 \sim 2030$ & $2031 \sim 2040$ & $2041 \sim 2050$ & $2051 \sim 2075$ & $2076 \sim 2100$ \\
\hline GDP growth & 8.7 & 7.9 & 7.0 & 6.6 & 5.9 & 5.6 & 5.5 & 4.6 & 3.9 \\
Labor growth & 0.4 & 0.5 & 0.0 & 0.0 & -0.3 & -0.3 & -0.4 & -0.6 & -0.9 \\
Capital growth & 12.6 & 9.4 & 8.4 & 7.8 & 6.7 & 6.2 & 5.9 & 5.4 & 4.8 \\
TFP growth & 0.9 & 2.0 & 2.0 & 1.9 & 2.0 & 1.9 & 1.9 & 1.9 & 1.8 \\
\hline
\end{tabular}

TABLE 2: Economic growth under the REG scenario in 2008-2100 (unit: \%).

\begin{tabular}{lccccccccc}
\hline & $2008 \sim 2010$ & $2011 \sim 2015$ & $2016 \sim 2020$ & $2021 \sim 2025$ & $2026 \sim 2030$ & $2031 \sim 2040$ & $2041 \sim 2050$ & $2051 \sim 2075$ & $2076 \sim 2100$ \\
\hline GDP growth & 8.7 & 8.4 & 7.2 & 6.6 & 5.8 & 5.7 & 5.6 & 4.9 & 4.3 \\
Labor growth & 0.4 & 0.5 & 0 & 0 & -0.3 & -0.4 & -0.4 & -0.8 & -1.2 \\
Capital growth & 12.6 & 9.2 & 7.5 & 6.8 & 5.5 & 4.6 & 3.9 & 2.9 & 2.1 \\
TFP growth & 0.9 & 2.7 & 2.7 & 2.6 & 2.6 & 2.6 & 2.5 & 1.9 & 1.8 \\
\hline
\end{tabular}

In the scenario of BAU, it assumes that urbanization and industrialization will continue to be pushed forward, the level of urbanization will increase $0.35-0.55 \%$ per year, and it will be expected to be $52 \%$ in $2015,65 \%$ in 2030 , and up to around $70 \%$ in 2050 . Taking into account the international economic environment and comparative advantage changes in China, export growth rate will gradually reduce in this kind of scenario. The trade surplus will continue to exist in a long time with a gradually declining trend and achieve the basic balance between import and export by 2050 and would rise steadily in 2050-2100 (Table 1).

4.2.2. Control Scenario One: REG Scenario. In the REG scenario, it assumes that the reforms will be putted forward quickly and smoothly, the role of market in the allocation of resources will be enhanced obviously, structural adjustment will be vigorously promoted, and the economic growth pattern will make progress. The specific settings include: (1) the price of all kinds of resources will be straightened out, and there will be a more rational allocation for resources. The external cost of economic activities will be internalized by the means of taxation, energy, and resource use efficiency will be improved. (2) We adjust the public expenditure structure of government and increase the proportion of the expenditure of education, medical and scientific research, and social welfare. Many studies have found that the low proportion of government spending on public services is one of the significant reasons leading to a lower consumer will, so adjusting the structure of government spending is helpful to expand the consumption, and promote the coordinated development of the structure of consumption and investment. (3) Eliminate the barriers to labor force immigration and accelerate the process of urbanization. Urbanization is the significant drivers to promote the optimal allocation of resources, economic growth, and industrial structure adjustment. (4) Intensify to the development of support service and industrial structure was further upgraded. In this model, the accelerated development of services is reflected by the higher TFP growth and lower tax levels (Table 2).

4.2.3. Control Scenario Two: CES Scenario. CES scenario mainly considers the following aspects of changes: (1) slower urbanization. Slower urbanization not only restricts the smooth and effective immigration of labor force, but also the upgrading of consumption structure and industrial structure optimization. (2) Slow recovering of the world economy, serious trade protection, and slow export growth. Exports are the significant motive force of economic growth, the annual growth rate of China's exports has been over $20 \%$ since 2000. The proportion of exports to GDP has also gradually increased, which was about $23.3 \%$ in 2000 , while the proportion of exports to GDP (including goods and services) reached $36.9 \%$ in 2008 with an increase of $13.6 \%$ during 8 years. In the situation with slow economic growth, industrial structure adjustment, and optimization will also be more difficult. (3) Higher international energy prices and restricted energy imports. In recent years, with the rapid economic development, the dependence on some kinds of resources especially crude oil and iron ore was also rising. In 2007, China produced 186 million tons of crude oil and imported 211 million tons, so the imports have exceeded domestic production. Once the international energy and resource prices rise, energy imports are restricted, which will be a greater constraints to economic development. (4) Slow progress in system reform and slow technological innovation and efficiency improvement. If the innovation ratio is slow, it may cause slow efficiency improvement, and result in the slow conversion of development patterns and slow growth rate. Under this scenario, the TFP value is lower than that under the BAU scenario by $0.4 \%$ (Table 3 ).

\section{Land Use Changes under Different Scenarios}

5.1. Accuracy Analysis of Land Use Simulation. GCAM model was applied to simulate the land use for the cultivated land, forestry area, grassland, built-up area, and unused land in 1990, 2005, and 2010. We took an accuracy analysis of land use simulation according to the comparison of simulated land use and real land use in 1990, 2005, and 2010 (Figure 2, Table 4).

As seen from the comparison of simulation results and real land use in 19902005 and 2010 in Figure 2, it is found that the simulation results is similar with the real land use change. Cultivated land show increases due to population 


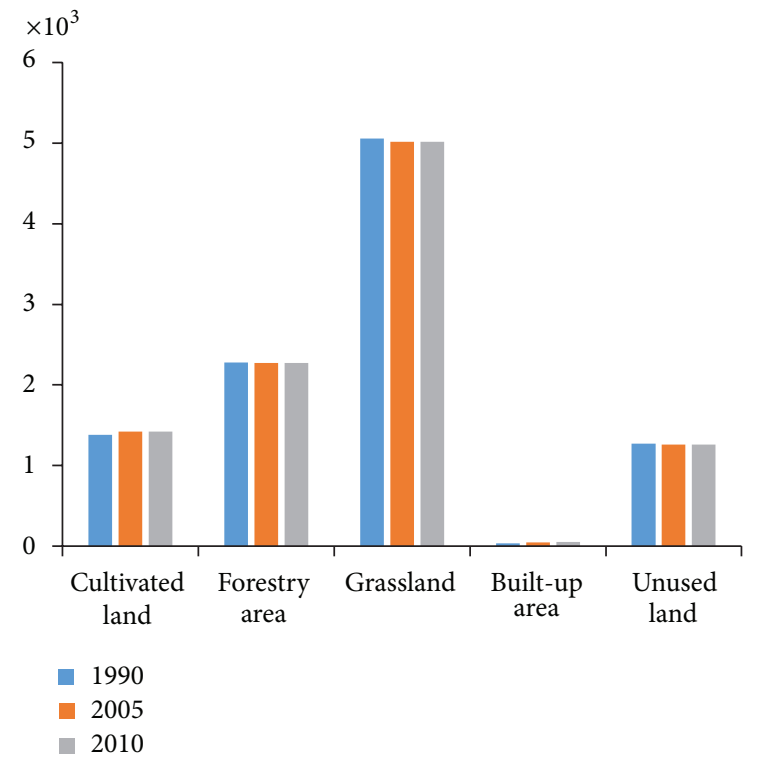

(a)

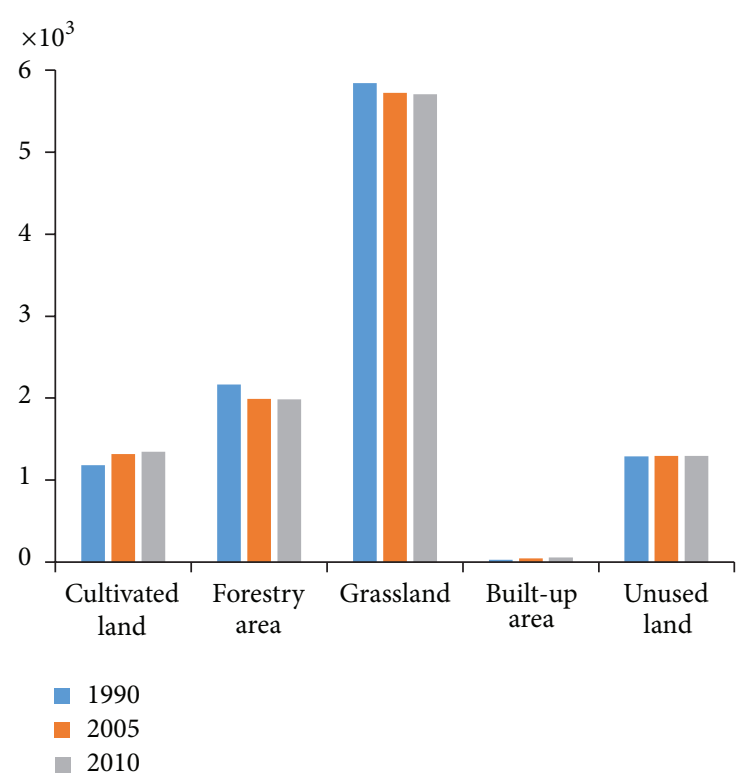

(b)

Figure 2: Comparison of simulated land use and real land use: (a) the real land use area in 1990, 2005, and 2010; (b) simulated land use area in 1990, 2005, and 2010 (unit: $1000 \mathrm{~km}^{2}$ ).

TABLE 3: The economic growth under the CES scenario in 2008-2100 (unit: \%).

\begin{tabular}{lccccccccc}
\hline & $2008 \sim 2010$ & $2011 \sim 2015$ & $2016 \sim 2020$ & $2021 \sim 2025$ & $2026 \sim 2030$ & $2031 \sim 2040$ & $2041 \sim 2050$ & $2051 \sim 2075$ & $2076 \sim 2100$ \\
\hline GDP growth & 8.7 & 7.0 & 5.7 & 5.1 & 4.3 & 3.5 & 2.8 & 2.6 & 2.3 \\
Labor growth & 0.4 & 0.5 & 0.0 & 0.0 & -0.3 & -0.3 & -0.4 & -0.5 & -0.8 \\
Capital growth & 12.6 & 9.2 & 6.9 & 6.1 & 4.9 & 4.2 & 3.4 & 2.5 \\
TFP growth & 0.9 & 1.3 & 1.6 & 1.4 & 1.5 & 1.3 & 1.2 & 1.8 & 0.9 \\
\hline
\end{tabular}

growth and domestic demand expansion. A larger demand for timber because of social and economic development, so that forestry area shows a downward trend overall, but the decreasing ratio is declining. As for the grassland, overgrazing has caused serious area shrinking. In the past decades, with a rapid economic development, urbanization is rising all the way and it brings about the built-up area keeping expanding in recent years. The unused land are assumed to be unchanged in the GCAM model, it would not be concerned about in future simulation. Besides, according to the accuracy analysis in Table 4, the total average error is about $8.67 \%$, which shows good simulation accuracy. So it is proper to simulate the land use change trends of China.

\subsection{Simulation of Land Use Change under Three Scenarios}

5.2.1. Land Use Change under BAU Scenario. In the BAU scenario, using GCAM model we simulated and obtained land use change trends in the drive of inertial socioeconomic growth (Figure 3).

As shown in Figure 3, under BAU scenario, cultivated land increases first and then decreases. The total forestry area is relatively stable, while the managed forestry area show a downward trend during 1990-2005, then increased gradually after 2005, and stabilized in 2080. The unexplored forestry area reduces before 2080, and then step into a stage of steady increase. Due to expansion of the range of human activities, the managed grassland goes up until 2065, and then it is in a steady stage during 2065-2095. As for the unexplored grassland, it declines from 1990 to 2050 and tends to be stable after then. The total grassland also decreases first and then becomes in a stable condition. Urban area under BAU scenario has no significant expansion, but it will still increase steadily, and the extent is relative small. Because of the current rapid development, more food demand requires more cultivated land, thus, cultivated land increases rapidly, and it will reach the maximum before the middle of 21st century. With the technological development, agricultural productivity increases gradually, and the decreasing dependence on cultivated land needs less cultivated land, so that cultivated land decreases all the way since the middle of 21st century, and the rate of declining will gradually increase first and then gradually decrease.

5.2.2. Land Use Change under REG Scenario. In REG scenario, socioeconomic development accelerated, under the drive of socioeconomic and, simulation results with GCAM model, we obtained the land use change trends (Figure 4).

The simulation results of land use under the REG scenario show that the obvious land use characteristics is that urban 


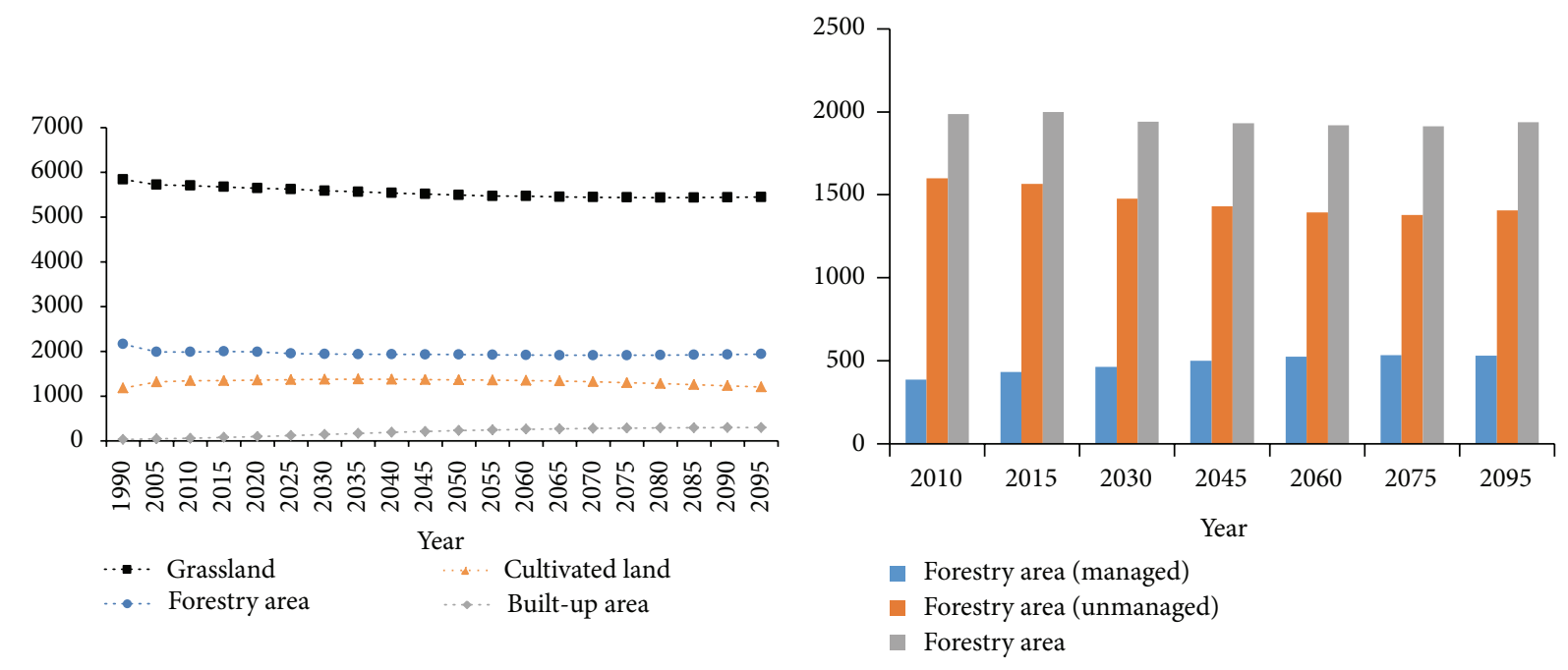

(a)

(b)

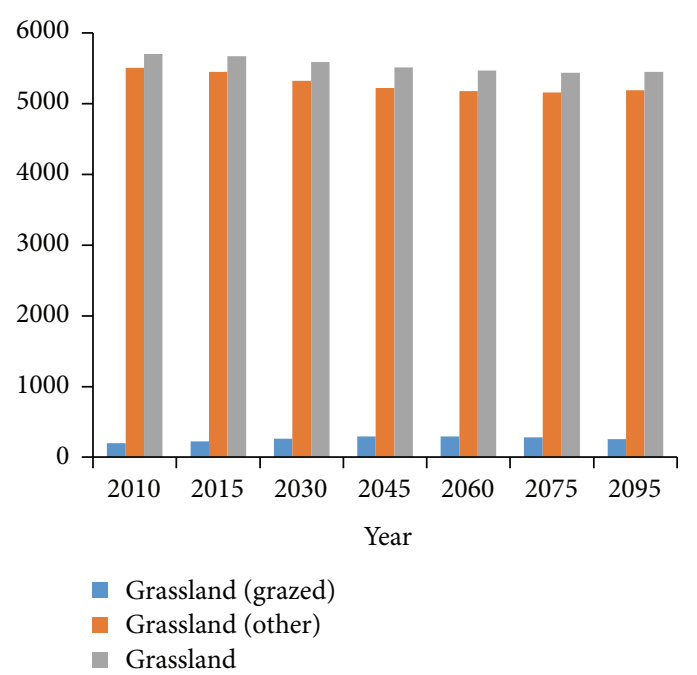

(c)

FIGURE 3: Land use change trends of China under BAU scenario during 1990-2095: (a) land use change trends of cultivated land, forest land, grassland, and built-up land; (b) trends of managed and unmanaged forest land; (c) trends of grazed and other grassland (unit: $1000 \mathrm{~km}^{2}$ ).

TABLE 4: The simulation accuracy of land use allocation (unit: \%).

\begin{tabular}{cccccccc}
\hline & Cultivated land & Unused land & Forestry area & Grassland & Built-up area & Average error & Total average error \\
\hline 1990 & $-14.63 \%$ & $-5.06 \%$ & $15.61 \%$ & $-12.72 \%$ & $1.74 \%$ & $9.95 \%$ & \\
2005 & $-7.50 \%$ & $3.23 \%$ & $-12.35 \%$ & $14.03 \%$ & $-2.85 \%$ & $7.99 \%$ & $8.67 \%$ \\
2010 & $-5.21 \%$ & $2.93 \%$ & $-12.56 \%$ & $13.75 \%$ & $5.92 \%$ & $8.07 \%$ & \\
\hline
\end{tabular}

area increased significantly due to the rapid urbanization. Cultivated land still increases first during 2010-2035 and then decrease after then. Accelerated economic development promotes the rising demand for timber, so as shown in Figure 4 the total forestry area decreases significantly, and the explored forestry area increases all the way. Rapid economic development accelerate the scarcity of resources; moreover, the demand gap will be widened under the development scenario, so the total area of grassland is in a downward trend, the unexplored grassland reduces all the way, while the explored grassland grows obviously. Under this scenario, it can be seen than explored grassland has been seriously damaged due to the grazing.

5.2.3. Land Use Change under CES Scenario. In CES scenario, the speed of socioeconomic development slowed down; under the drive of socioeconomic and simulation results with GCAM model, we obtained the land use change trends (Figure 5). 


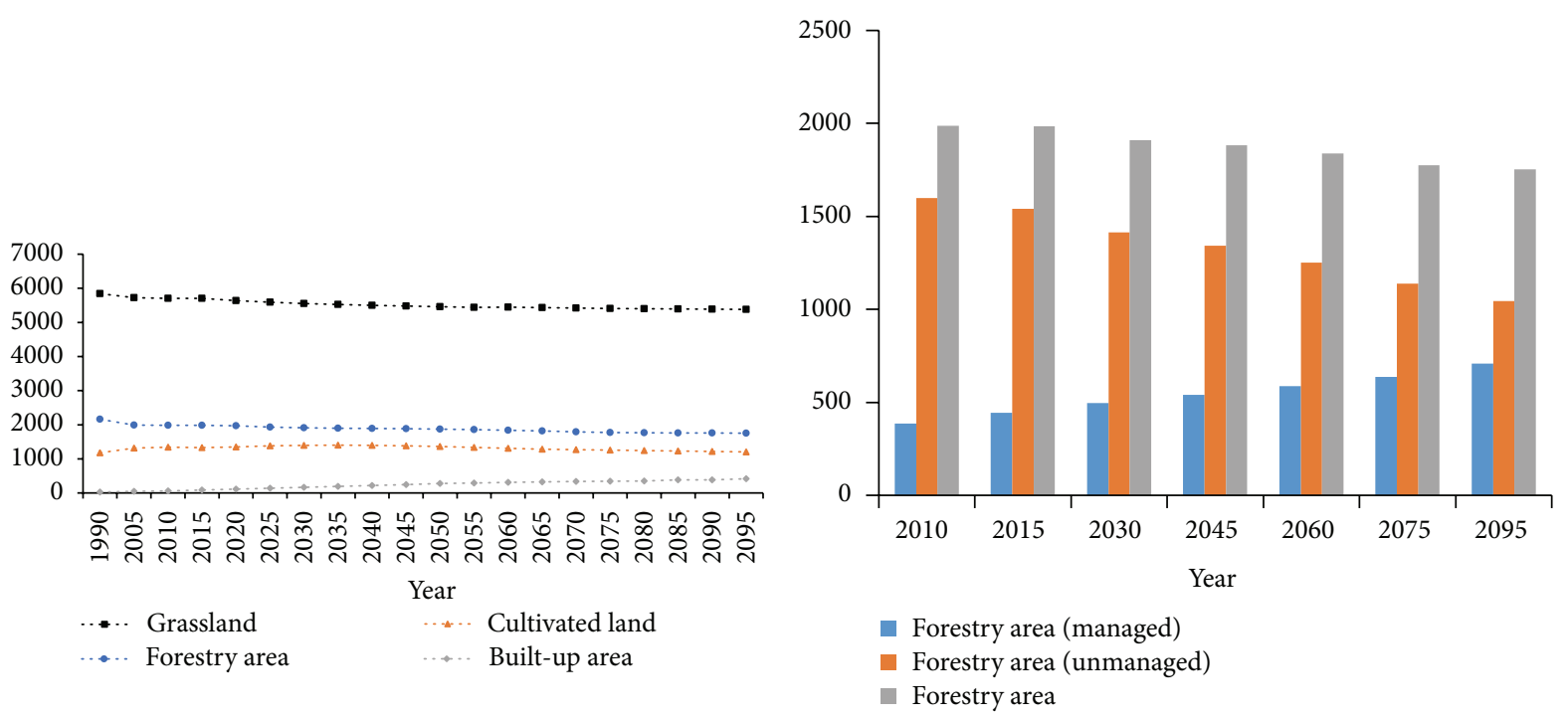

(a)

(b)

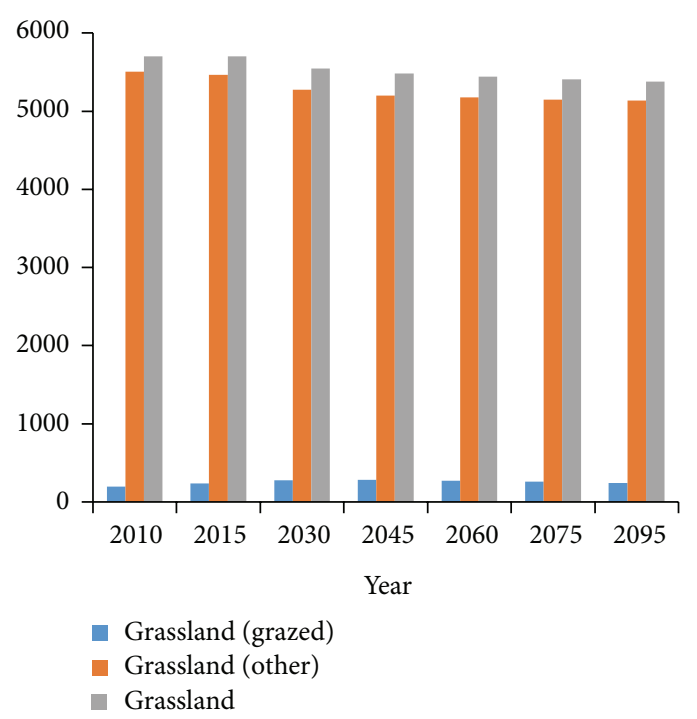

(c)

FIGURE 4: Land use change trends of China under REG scenario during 1990-2095; (a) land use change trends of cultivated land, forest land, grassland, and built-up land; (b) trends of managed and unmanaged forest land; (c) trends of grazed and other grassland (unit: $1000 \mathrm{~km}^{2}$ ).

According to Figure 5, cultivated area increases from 1990 to 2035 and decrease after then under CES scenario. As for the forestry area, the implementation of conservation measures has protected the forestry area excellently, so the forestry area increases all the way from 2005 to 2050, although it decreases during 1990-2005. After 2050, it will make small range of reduction. The unmanaged forestry area has been reduced all the time, while it will rise after 2070. The total forestry area decreases first and then there is an increase trend due to the implementation of environmental conservation strategy. Grassland decreases during 1990-2030 and then increase after 2030. According to Figure 5, the unexplored grassland has been in a downward trend during 1990-2065, and then become stable after 2065, while the explored grassland increases obviously. Therefore, CES scenario has positive effect on the protection of environment, and it is consistent with the model of sustainable development and low-carbon economic development. Of course, urbanization still plays an irreplaceable positive role in the process of socialeconomic development, and the built-up area also has an increasing trend under CES scenario.

\section{6. $\mathrm{CO}_{2}$ Emissions Resulting from Land Use Change}

As shown in Figure 6, under the BAU scenario, $\mathrm{CO}_{2}$ emissions will have a certain amount of increase in the coming decades and begin to drop down around 2065; however, it will be extremely slow. $\mathrm{CO}_{2}$ emissions will continue to accumulate over the next 50 years, and $\mathrm{CO}_{2}$ emissions are 


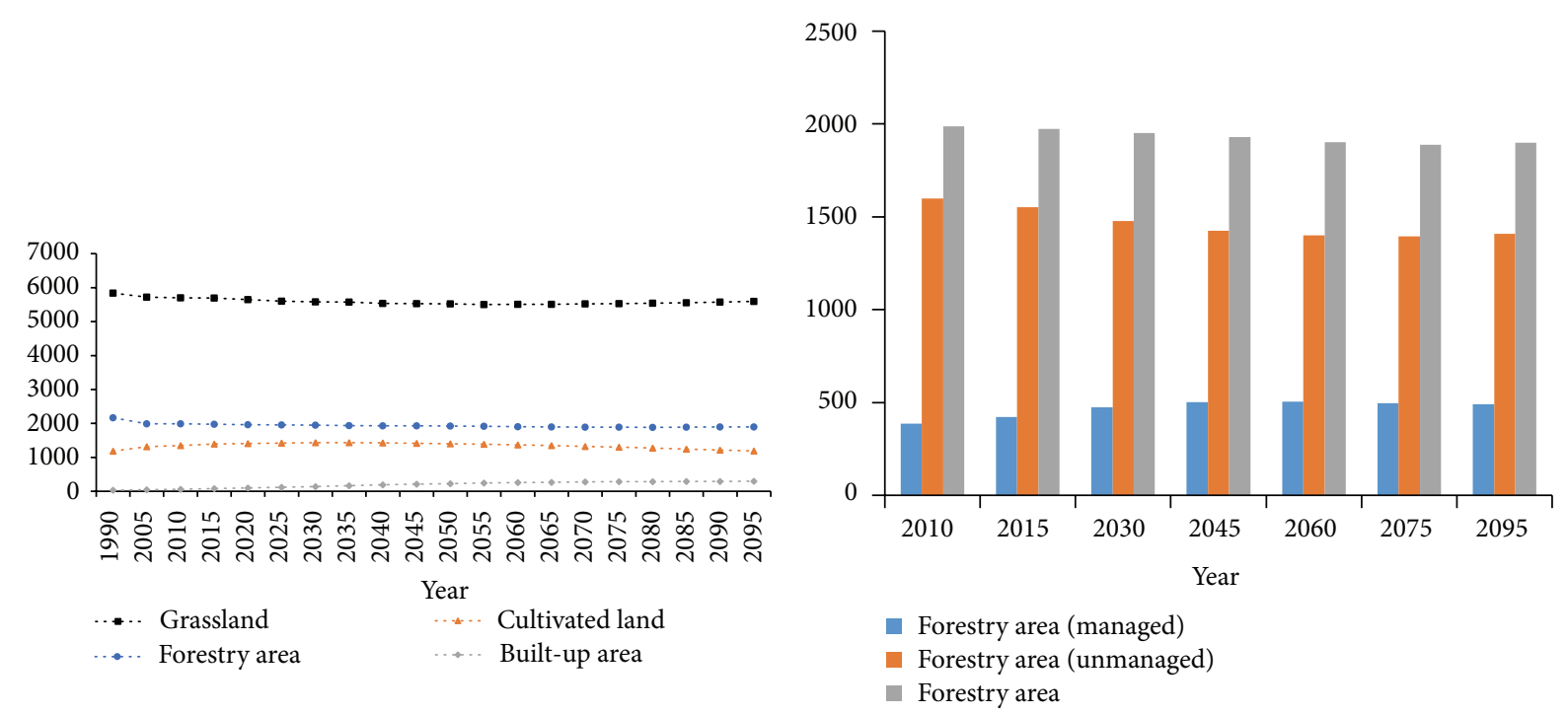

(a)

(b)

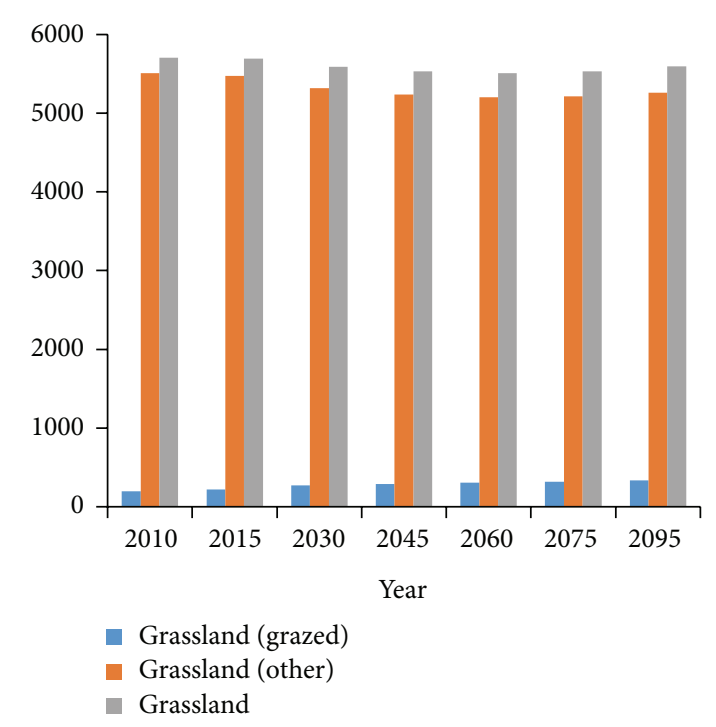

(c)

FIGURE 5: Land use change trends of China under CES scenario during 1990-2095: (a) land use change trends of cultivated land, forest land, grassland, and built-up land; (b) trends of managed and unmanaged forest land; (c) trends of grazed and other grassland (unit: $1000 \mathrm{~km}^{2}$ ).

maintained at the relative high level for a long time under the BAU scenario. Therefore, although it will not cause the serious pressure on the environment under the BAU scenario, the negative effect is still profound, and it is not suitable for the current environment. Under the REG scenario, $\mathrm{CO}_{2}$ emissions are at a higher level compared with the other two kinds of scenarios. $\mathrm{CO}_{2}$ emissions have the rising trend all the time. The greenhouse effect is serious currently, so controlling the $\mathrm{CO}_{2}$ emission is the primary objective of developing the low carbon economy around the world. It can be seen from the simulation results of the REG scenario, although it can obtain the rapid economic development, it is contrary to the strategic goal of sustainable development. Therefore, the REG scenario cannot meet the requirements of social development. It is different under the CES scenario $\mathrm{CO}_{2}$ emissions are beginning to show a downward trend in 2030 and have maintained a low level after 2070, close to the level in 1990s. This kind of scenario is beneficial to protect environment and relieve the environmental pressures in line with the strategic objectives of sustainable development. Besides, it ensures the steady development of social economy as well. Therefore, this kind of scenario achieves double win, not only protect the environment, but also promote the economic development. Thus, the CES scenario is the most suitable scenario.

\section{Conclusions and Discussion}

In this study, three kinds of scenario; that is, BAU scenario, REG scenario, and CES scenario are designed. We use the 


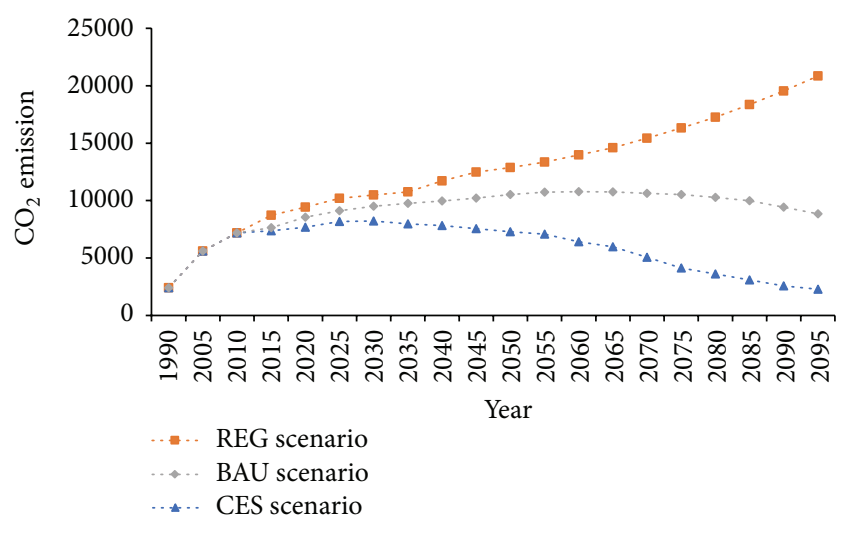

FIgURE 6: $\mathrm{CO}_{2}$ emissions under three scenarios during 1990-2095 (unit: MTC).

GCAM model to simulate the land use change from 2015 to 2095 and estimate the impact of land use on $\mathrm{CO}_{2}$ emissions under the drive of social economy and finally find which kind of land use change can adapt to climate change. The conclusions are obtained as follows.

(1) The BAU scenario kept the development trend in the past decades, and there is still a relatively high speed of economic development. However, it needs time to digest and absorb the great achievements brought by rapid economic development in the coming period in order to make all the aspects adapt to the development requirement, such as the promotion of the environmental protection technology, the rationalization of emission standard, and the further narrowing of urban and rural gaps. When the whole society adapts to the economic development achievements, the bubble economy cannot be formed, and the future economy will show more steady improvement. The simulation results indicate that the $\mathrm{CO}_{2}$ emissions will be at an extreme high level for a long time in China under the BAU scenario. The government should take the appropriate measures or polies at different stages to meet the real requirements of socialeconomic development. Therefore, the baseline scenario is not suitable for the future $\mathrm{CO}_{2}$ emission control.

(2) Under the REG scenario, the rapid growth of GDP and population brings about the increasing pressure on the environment. The adjustment of industrial structure especially the rising proportion of secondary industry will lead to the growing of energy consumption and demand, the total amount of exploitation and import of oil, while natural gas and coal is obviously increasing. Besides, the rapid urbanization will consume more energy and resources. According to the simulation results of this scenario, $\mathrm{CO}_{2}$ emissions will rise sharply and stay at an extreme high level, and it does not meet the sustainable development and low-carbon economic development model. Moreover, this scenario will lead to serious environmental crisis. Therefore, it is undesirable.

(3) The CES scenario focuses on the purpose of environment protection and controls the growth rate of GDP and population. The setting for the urbanization level is consistent with the one under the BAU scenario in order to avoid further pressure on the environment. And the adjustment of industrial structure is to vigorously develop the tertiary industry to reduce the proportion of the first industry and control the development of the secondary industry. Under this scenario, the industrial structure optimization can be sped up, and the $\mathrm{CO}_{2}$ emission can be effectively controlled. Therefore, this kind of scenario is more suitable for China.

This study is closely related with the socioeconomic factors and climate change through taking the land use change as the core influencing factor of climate change and the socioeconomic development as the driving force, and the results of this study are of great practical significance and far-reaching research value. However, there are still some shortcomings in this study. At first, there are various factors of the socioeconomic development, which were not taken into account in the scenario design. Therefore, it is necessary to implement more detailed analysis of the socioeconomic drivers of land use change in the future study. What's more, the impacts of socioeconomic factors on the land use change are represented in the approach parameterization, which have some limitations since they failed to thoroughly reveal how the socioeconomic development influences land use change. Meanwhile, only three scenarios, which can set the general direction of socioeconomic development, were designed in this study, but they cannot provide more specific details. Therefore, more scenarios should be designed in the future research so as to fully reveal the best land use change to adapt to the climate change, for example, more specific scenarios of the same type can be designed under the CES scenarios.

\section{Acknowledgments}

This research was supported by the China National Natural Science Funds for Distinguished Young Scholar (Grant no. 71225005), the National Key Program for Developing Basic Science in China (Grant no. 2010CB950900), and the Exploratory Forefront Project for the Strategic Science Plan in IGSNRR; CAS is also greatly appreciated.

\section{References}

[1] M. Yan, Z. Wang, J. Kaplan, J. Liu, S. Min, and S. Wang, "Comparison between reconstructions of global anthropogenic land cover change over past two millennia," Chinese Geographical Science, vol. 23, no. 2, pp. 131-146, 2013.

[2] X. Deng, J. Han, and F. Yin, "Net energy, $\mathrm{CO}_{2}$ emission and land-based cost-benefit analyses of Jatropha biodiesel: a case study of the Panzhihua region of Sichuan province in China," Energies, vol. 5, no. 7, pp. 2150-2164, 2012. 
[3] W. Wu, J. Huang, and X. Deng, "Potential land for plantation of Jatropha curcas as feedstocks for biodiesel in China," Science in China Series D, vol. 53, no. 1, pp. 120-127, 2010.

[4] L. Jiang, X. Deng, and K. Seto, "The impact of urban expansion on agricultural land use intensity in China," Land Use Policy, vol. 35, pp. 33-39, 2013.

[5] L. Jiang, X. Deng, and K. Seto, "Multi-level modeling of urban expansion and cultivated land conversion for urban hotspot counties in China," Landscape and Urban Planning, vol. 108, no. 2-4, pp. 131-139, 2012.

[6] J. Liu and X. Deng, "Progress of the research methodologies on the temporal and spatial process of LUCC," Chinese Science Bulletin, vol. 55, no. 14, pp. 1354-1362, 2010.

[7] X. Deng, J. Huang, S. Rozelle, and E. Uchida, "Cultivated land conversion and potential agricultural productivity in China," Land Use Policy, vol. 23, no. 4, pp. 372-384, 2006.

[8] D. Jiang, D. Zhuang, Y. Huang, and J. Fu, "Survey of multispectral image fusion techniques in remote sensing applications," in Image Fusion and Its Applications, pp. 1-23, InTechOpen, 2011.

[9] X. Zhou and C. Kang, "Land use/cover change analysis in Wuhan city based on RS and GIS," in Proceedings of the 19th International Conference on Geoinformatics (Geoinformatics '11), pp. 1-5, June 2011.

[10] V. H. Dale, "The relationship between land-use change and climate change," Ecological Applications, vol. 7, no. 3, pp. 753-769, 1997.

[11] H. Hao and Z. Ren, "Land use/Land cover change (LUCC) and eco-environment response to LUCC in farming-pastoral zone, China," Agricultural Sciences in China, vol. 8, no. 1, pp. 91-97, 2009.

[12] B. Turner, R. Moss, and D. Skole, "Relation of land use and global land cover change: a proposal for an IGBP-HDP core project," IGBP Report, vol. 24 and IHDP Report, vol. 5, Stockholm, Sweden, 1993.

[13] J. Liu, Z. Zhang, X. Xu et al., "Spatial patterns and driving forces of land use change in China during the early 21st century," Journal of Geographical Sciences, vol. 20, no. 4, pp. 483-494, 2010.

[14] G. B. Bonan, "Forests and climate change: forcings, feedbacks, and the climate benefits of forests," Science, vol. 320, no. 5882, pp. 1444-1449, 2008.

[15] M. Wang, X. Zhang, and X. Yan, "Modeling the climatic effects of urbanization in the Beijing-Tianjin-Hebei metropolitan area," Theoretical and Applied Climatology, vol. 113, no. 3-4, pp. 377-385, 2013.

[16] E. Kalnay and M. Cai, "Impact of urbanization and land-use change on climate," Nature, vol. 423, no. 6939, pp. 528-531, 2003.

[17] D. Zhuang, D. Jiang, L. Liu, and Y. Huang, "Assessment of bioenergy potential on marginal land in China," Renewable and Sustainable Energy Reviews, vol. 15, no. 2, pp. 1050-1056, 2011.

[18] K. J. Anderson-Teixeira, P. K. Snyder, T. E. Twine, S. V. Cuadra, M. H. Costa, and E. H. Delucia, "Climate-regulation services of natural and agricultural ecoregions of the Americas," Nature Climate Change, vol. 2, no. 3, pp. 177-181, 2012.

[19] F. Li, X. Liu, D. Hu et al., "Measurement indicators and an evaluation approach for assessing urban sustainable development: a case study for China's Jining City," Landscape and Urban Planning, vol. 90, no. 3-4, pp. 134-142, 2009.

[20] Z. Hu, J. Yuan, and Z. Hu, "Study on China's low carbon development in an Economy-Energy-Electricity-Environment framework," Energy Policy, vol. 39, no. 5, pp. 2596-2605, 2011.
[21] X. Zhang, J. Han, H. Zhao et al., "Evaluating the interplays among economic growth and energy consumption and $\mathrm{CO}_{2}$ emission of China during 1990-2007," Renewable and Sustainable Energy Reviews, vol. 16, no. 1, pp. 65-72, 2012.

[22] J. Liu, M. Liu, D. Zhuang, Z. Zhang, and X. Deng, "Study on spatial pattern of land-use change in China during 1995-2000," Science in China Series D, vol. 46, no. 4, pp. 373-384, 2003.

[23] X. Deng, Y. Fang, Y. Lin, and Y. Yuan, "Non-parametric method for filling in the missing value for cross-sectional dataset: a validation on the per capita GDP data at county level in China," Journal of Food, Agriculture \& Environment, vol. 10, no. 3-4, pp. 1350-1354, 2012.

[24] A. Brenkert, S. Smith, S. Kim, and H. Pitcher, "Model documentation for the MiniCAM," PNNL-14337, U.S. Department of Energy, Pacific Northwest National Laboratory, Richland, Wash, USA, 2003.

[25] J. Edmonds, M. Wise, H. Pitcher, R. Richels, T. Wigley, and C. Maccracken, "An integrated assessment of climate change and the accelerated introduction of advanced energy technologies," Mitigation and Adaptation Strategies for Global Change, vol. 1, no. 4, pp. 311-339, 1997.

[26] J. Edmonds and J. Reilly, Global Energy: Assessing the Future, Oxford University Press, New York, NY, USA, 1985.

[27] J. Edmonds, J. Reilly, R. Gardner, and A. Brenkert, Uncertainty in Future Global Energy Use and Fossil Fuel $\mathrm{CO}_{2}$ Emissions 1975 to 2075, U.S. Department of Commerce, National Technical Information Service, Springfield, Va, USA, 1986.

[28] R. D. Sands and J. A. Edmonds, "Climate change impacts for the conterminous USA: an integrated assessment: part 7. Economic analysis of field crops and land use with climate change," Climatic Change, vol. 69, no. 1, pp. 127-150, 2005.

[29] R. D. Sands and M. Leimbach, "Modeling agriculture and land use in an integrated assessment framework," Climatic Change, vol. 56, no. 1-2, pp. 185-210, 2003.

[30] T. M. L. Wigley and S. C. B. Raper, "Implications for climate and sea level of revised IPCC emissions scenarios," Nature, vol. 357, no. 6376, pp. 293-300, 1992.

[31] M. Hulme, T. Jiang, and T. Wigley, SCENGEN: A Climate Change Scenario Generator, a Software User Manual, Climatic Change Research Unit, School of Environmental Sciences, University of East Anglia, Norwich, UK, 1995.

[32] B. Lin and J. Liu, "Estimating coal production peak and trends of coal imports in China," Energy Policy, vol. 38, no. 1, pp. 512519, 2010.

[33] W. Liu, H. Lund, B. V. Mathiesen, and X. Zhang, "Potential of renewable energy systems in China," Applied Energy, vol. 88, no. 2, pp. 518-525, 2011. 

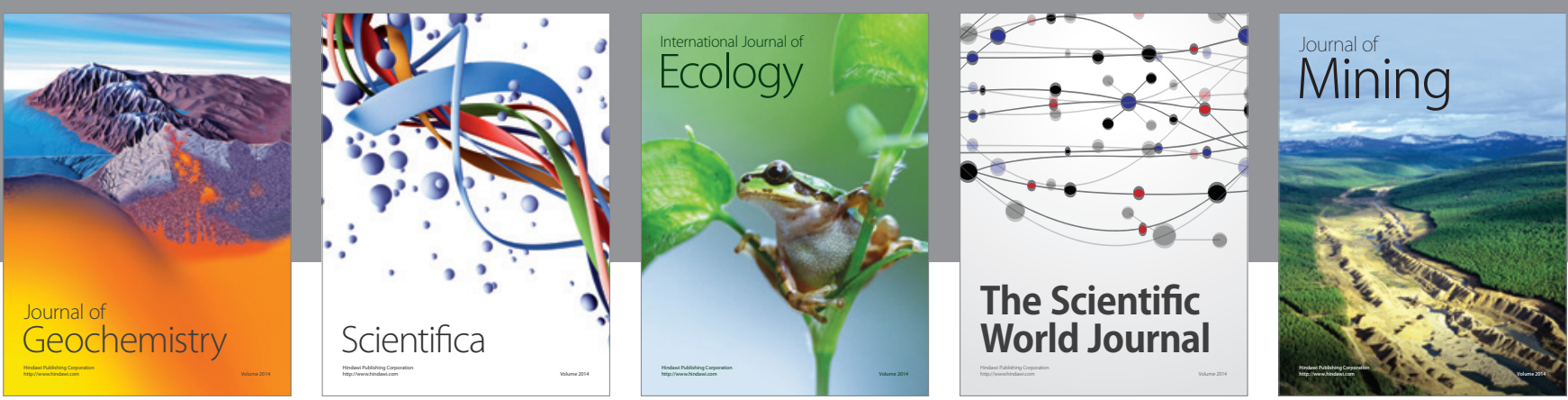

The Scientific World Journal
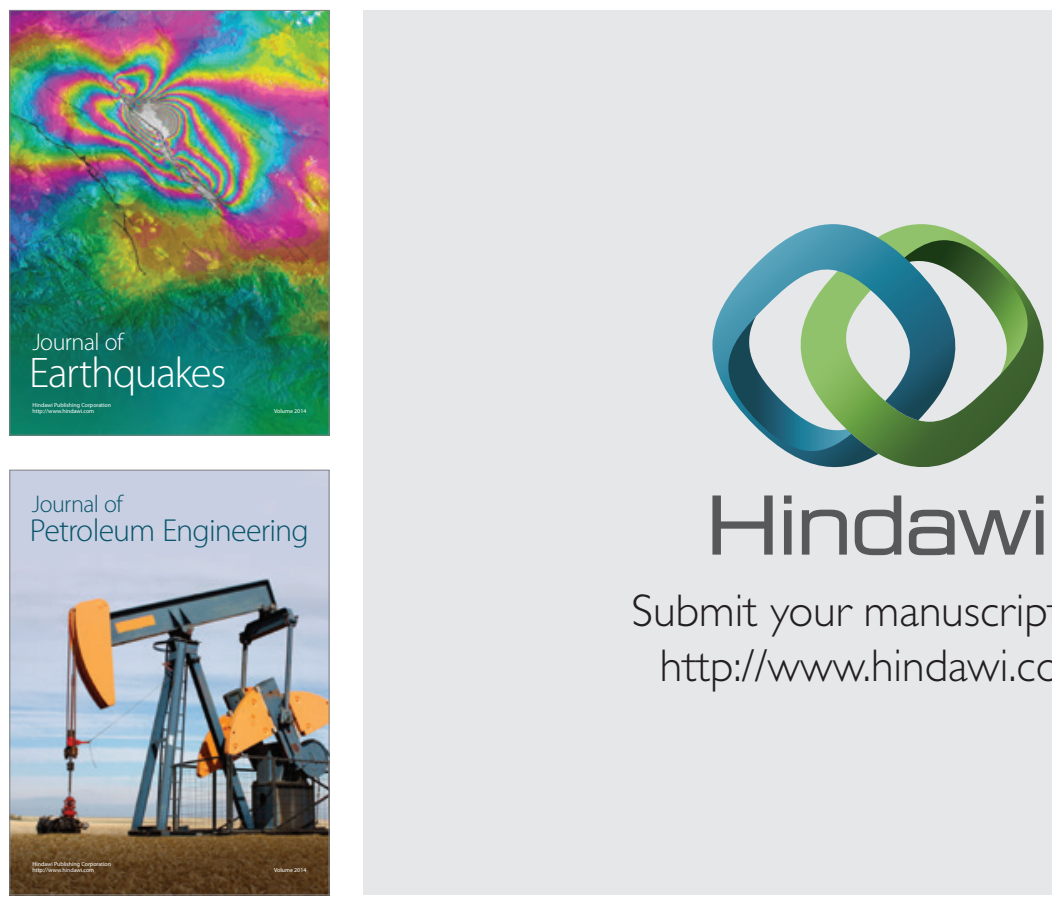

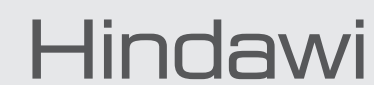

Submit your manuscripts at

http://www.hindawi.com
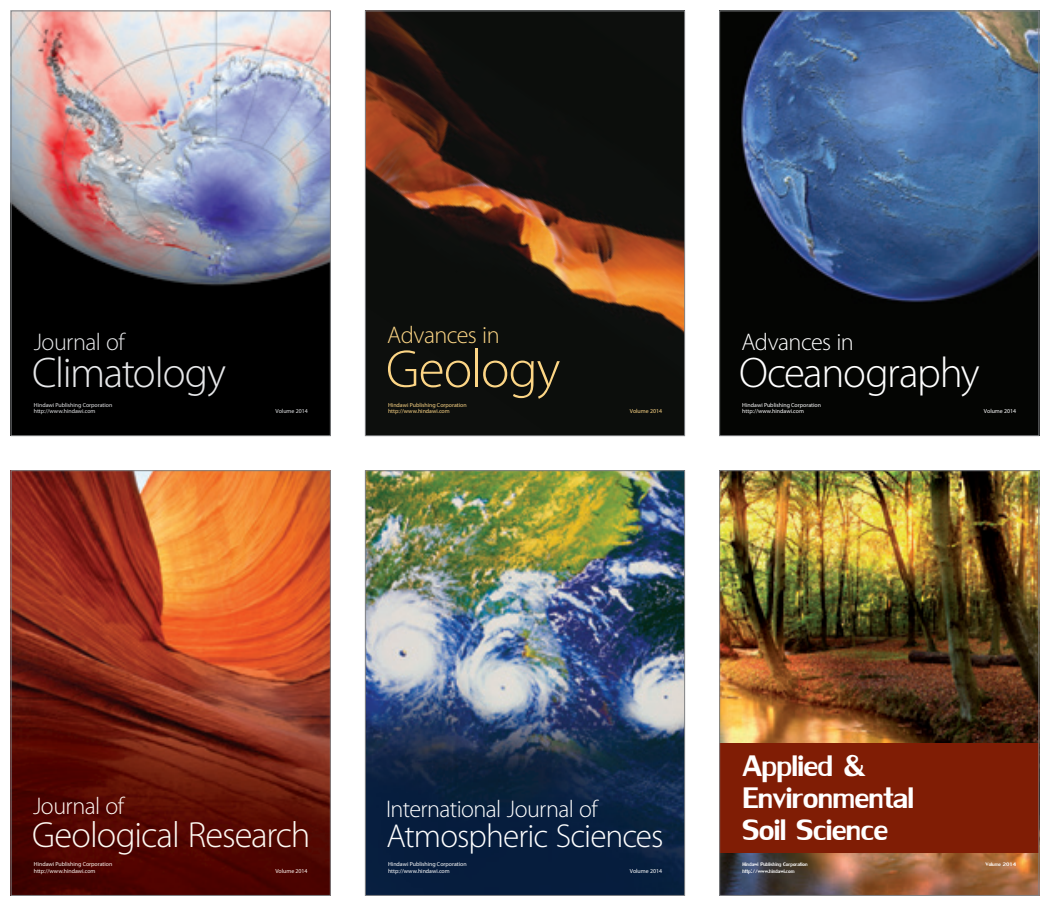
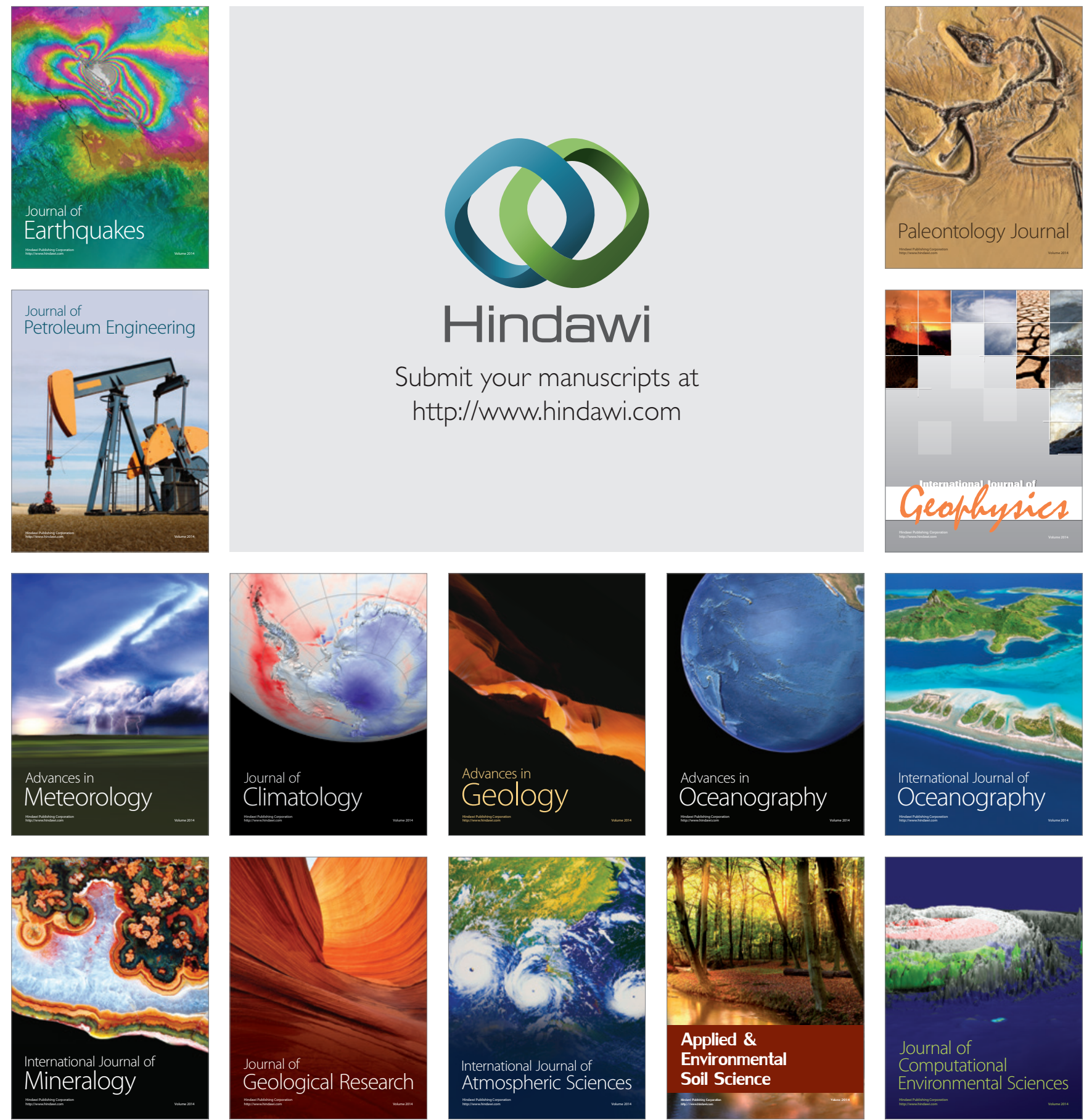